\title{
Improving Learner Retention in English Online Courses: Current Situation from a Center of Foreign Languages in Vietnam
}

\author{
Luu Nguyen Quoc Hung \\ Can Tho University, Vietnam \\ Email: lnqhung [AT] ctu.edu.vn
}

\begin{abstract}
Online learning has experienced rapid growth recently, particularly due to many schools' closures because of the Covid-19 pandemic. While the number of online learners is steadily growing, retaining learners in online courses and programs has posed a challenge. Retention rates are vital data that is indicative of an institution's ability to engage learners in their learning, satisfy their educational needs, and prevent them from dropping out. With the aim to explore possible reasons why learners drop out in their online learning and identify effective ways to improve learner retention, this study examines 164 online learners at a center of foreign languages through an online survey. The findings indicate that online learning is still a revolutionary trend of education and learner retention rates have been positive in most online courses. Practical recommendations are included so that institutions can use these results immediately to impact their policies and practices.
\end{abstract}

Keywords----- Covid-19, learner retention, online learning, success

\section{INTRODUCTION}

Online courses are a revolutionary trend of educational technology today. Since the Covid-19 pandemic, online classes have become the cornerstone of modern education. However, it is worth noting that while more learners are signing up for online classes, more are also dropping out. Online learner retention has been suggested as one of greatest weaknesses in online education [1]. In an increasingly competitive and results-oriented education market, learner retention is of key importance to institutions as learner retention is vital for the well-being of learners, programs, institutions, and even society.

While much has been written about learner retention in higher education contexts, relatively little has been written about the retention of learners in online programs at foreign language centers in which learner retention is directly linked with quality improvement efforts. This small-scaled study was conducted with 164 online learners through an online survey, examining their frequency of attending online classes as well as their perceptions towards current practices of improving learner retention in online classes at a center of foreign languages in Vietnam.

\subsection{Retention and retention rate}

\section{LITERATURE REVIEW}

Retention can be difficult to measure or define. In online learning literature, the terms retention and persistence are frequently employed interchangeably. Attempts to differentiate the terms have not been successful. For example, it has been suggested that retention is an institution-level measure of success, and that persistence is an individual or learnerlevel measure of success [2]. However, this differentiation of terms has not been widely accepted. In an educational context, retention is a measure of the rate at which learners persist in their educational program at an institution, expressed as a percentage.

There are generally two extremes of learner retention. Normal progression, typical of a stayer, or retained learner, occurs when a learner registers for a program until completion. A dropout, or leaver, is a learner who enters a program but leaves before completion. Retention rates are vital data that is indicative of the institution's ability to engage students in their learning, satisfy their student's educational needs, and prevent them from dropping out.

\subsection{Retention rates in traditional and online classes}

Online learning continues to grow faster than onsite learning, but overall online programs struggle with a lower retention rate [3]. Online learners tend to withdraw more often, compared to learners in traditional classrooms. Generally, retention rates for online courses have been calculated to be 10 to 20 percent lower than the retention rates for their inperson counterparts in a conventional program. Statistics of online education [4] show that E-learning increases retention rates from $25 \%$ to $60 \%$. Online literature reviews indicate that the online attrition pattern is not limited to any specific period. Learners may withdraw from online classes anytime during the program or at any level of their learning process. 


\subsection{Factors influencing online learner retention}

There are a number of factors that determine whether a learner will stay and complete a program. Lee and Choi [5] examined research targeting retention in online courses and suggested groups of reasons affecting learner retention: course/program factors, teacher factors and environmental factors.

About the program, the difficulty level of the academic program or subject matter was an influential determinant of learner retention in online courses. Revealed by Boston and his colleagues [6], learners tended to drop out when the curriculum or program was found to be too easy or too difficult. About teachers, online learners generally expect active facilitation from teachers to promote learners' social interaction and engagement. In addition, learners appreciate teachers to foster their knowledge acquisition and guidance for promoting topic understanding. Environmental factors mainly include support services such as advising, tutors, and technical support.

\subsection{CFL and its online programs}

The Center of Foreign Languages, Can Tho University (hereafter referred to as the Center or CFL) has provided varieties of fee-paid courses of foreign languages and began with more online classes during the country's social distancing due to the Covid-19 pandemic. Currently, there are two types of online programs in terms of study purposes. One group of online classes is for general English purposes, and the second group is for exam preparation such as IELTS, TOEIC or VSTEP. The class size is relatively small, from 15 to 24 learners. The teachers generally use Zoom meeting as a technical tool of their instruction. The course duration is between 8 and 10 weeks.

\subsection{Methods}

\section{METHODS AND RESULTS}

\subsubsection{Participants}

Participants of the study were current learners of online programs. Two groups of online classes with total 336 learners: one group of exam preparation and one of general English were checked for learner attendance during the eightweek program. In the last week of the program, learners were invited to complete an online survey. There were 164 out of $336(48.8 \%)$ participants completing the survey. The basic characteristics of the participants are shown in Table 1.

Table 1. Demographic characteristics of the participants in the survey $(\mathrm{N}=164)$

\begin{tabular}{|c|c|c|}
\hline Characteristics & Number & Percentage \\
\hline Gender & & $52.4 \%$ \\
Female & & $47.6 \%$ \\
Male & & $84.8 \%$ \\
Student & & $15.2 \%$ \\
Employee & 130 & $79.3 \%$ \\
Exam preparation & 34 & $20.7 \%$ \\
\hline General English & & \\
\hline
\end{tabular}

\subsubsection{Instrument}

The learners of the current online courses were invited to respond to an online survey. There are two main sections in the questionnaire. The first section is about participant's information, and the second section consists of three open questions about reasons of class dropouts, suggestions for improving online courses, and choice of learning mode in the future.

\subsection{Results}

\subsubsection{Frequency of class attendance}

Overall, the percentage of learner retention of both groups is relatively high (Table 2). For the Exam preparation group, the retention rate is $77.38 \%$ and $79.31 \%$ for the General English group. It is relatively natural that the downward trend occurs during the program, particularly with the Exam preparation group. However, with the General English group, there is a slight fluctuation movement when in the last two weeks the learner retention is somewhat high again. 
Table 2. Learner retention rates

\begin{tabular}{|c|c|c|}
\hline Week & $\begin{array}{c}\text { Exam preparation group } \\
\text { (\% of learner attendance) } \\
\mathrm{N}=\mathbf{2 1 5} \\
\end{array}$ & $\begin{array}{c}\text { General English group } \\
\text { (\% of learner attendance) } \\
\mathrm{N}=\mathbf{1 2 1}\end{array}$ \\
\hline 1 & 90.85 & 89.53 \\
\hline 2 & 79.84 & 86.23 \\
\hline 3 & 83.57 & 76.86 \\
\hline 4 & 79.84 & 76.86 \\
\hline 5 & 76.90 & 74.66 \\
\hline 6 & 73.18 & 71.07 \\
\hline 7 & 67.75 & 75.76 \\
\hline 8 & 67.13 & 83.47 \\
\hline $\begin{array}{c}\text { Overall } \\
\text { percentage }\end{array}$ & 77.38 & 79.31 \\
\hline
\end{tabular}

\subsubsection{Reasons of class dropouts}

While the percentage of learner retention in both online programs is relatively high in this study, the number of dropouts needs further consideration. There are 61 participants $(32.2 \%)$ reporting that they were fully attending the classes; however, over $60 \%$ of the participants indicated different reasons of their absence from some classes during the program. The generally indicated reasons can be classified into some main categories.

The most common reason why most learners (with 39 participants) could not attend classes is because they were busy with family or work duties. Also, there were 20 participants reporting that they could not manage online classes due to busy schedule of learning at schools or universities. The results are somewhat in line with online literature, stating that scheduling and time constraints are usually the concern of online learners [7]. Examples of learners' comments in this category included:

- I love to study but my work schedule is very irregular; usually I cannot manage the time for my class.

- My busy workload stops my attending class on time and I have to cancel several classes.

- My exam schedule in my college is at the same time with my online class.

Some participants also reported health problem as a reason for their absence from some online classes, although learners' illness can be a common reason of class dropout for both onsite and online courses.

Other common reasons of learner dropouts are problems of Internet connection and electricity supply. There are 17 participants reporting that their online classes were interrupted or canceled due to unstable Internet connection in their areas. Some participants reported:

- My Internet connection is very weak. It is a nuisance to stay connected and study.

- My learning is not effective because the wifi usually goes down.

- I have to reconnect zoom twice or more during the class session due to unstable Internet. Sometimes I could not stay for my study.

The power supply was also a reported issue in this study when 5 participants shared this problem. - It is not very common, but during this course I had to stop my class two times due to the power supply.

The online format of the course was challenging for a number of learners in this study. Several participants had issues relating to online technology such as being confused by the Zoom access or online directions. Some common comments were:

- I hardly followed the course at the beginning due to many technical issues.

- The course should have better guideline and orientation for some learners without good background of technology.

Another direct cause for class dropout is due to learner dissatisfaction with online learning. Although not many participants reported this reason (13 out 164 participants), this problem needs further consideration to improve learner retention.

- Online learning is boring.

- I am not comfortable with online learning. I prefer traditional classrooms.

- Online learning is not my choice. I had no choice due to the Covid-19 pandemic.

\subsubsection{Suggestions for improving online classes}

Participants were also invited to suggest ways for improving online courses. It is interesting to note that over half of the participants $(61.6 \%)$ reported their satisfaction with the program and had no specific suggestion. Most responses focus on teachers and their pedagogy, course contents and online materials, the class schedules, technology support and online course directions. 
Online teachers have an essential role in helping prevent learner attrition by creating a comfortable online learning environment where learners can build community and establish trust [8]. In this study, eight participants had suggestions directly related to online teachers' role. Their comments included:

- Teacher should be more helpful to facilitate learners with basic knowledge.

- Teachers need to be friendly and sharing.

Regarding to teaching techniques or methods, several participants suggested having better interaction between teachers and learners and also among learners. Learning outcomes need to be informative, and instant and continuous feedbacks are encouraged. Assessments should also be measurable and realistic in online setting. Some participants shared their views:

- I like my teachers to have more interaction activities.

- Teachers should provide instant feedback.

- The lesson objectives need to be informed and reviewed in every lesson.

Another common theme for improving the program was the importance of course content in online courses. The teaching content should align with the learning outcomes and assessment strategies. The course should equip learners with sufficient vocabulary and develop language skills of listening, speaking, reading and writing. Some comments included:

- The content should be practical.

- During the course, I need to enhance language skills, especially listening and speaking.

- I like to have more vocabulary exercises in this course.

Online learning materials can be accessible through different kinds such as texts, images, sounds, videos. With online learning, the material should be designed to engage learners with more practical activities. A number of participants indicated that their learning would be better with more practical learning resources. Most participants would like to have more self-learning materials, particularly on the E-learning system.

- Online materials need more interaction activities.

- The course would be more practical if there were more self-learning exercises.

The class schedule or course duration is also a concern some participants would like to improve. Although they were overall satisfactory with the program, several participants suggested extending the course length for further practice.

- I prefer to have more time for this online course as I feel the course duration is somewhat limited.

- The lesson sessions can be shorter for more concentration but the course length can be extended.

Another theme of suggestions reported by numerous participants is about technical and online learning supports. As online classes are vastly different to in-person learning, it is important that learners should understand what to expect when they participate in a virtual classroom. Confusion can result in learning cancellation, whereas clarity generally can foster learner engagement [9]. In a similar vein, in this study, the participants suggested:

- The program should provide more technical supports through zalo group.

- I like to have detailed information of course requirements.

\subsubsection{Future learning}

On the question "Will you continue with online learning in the future?", it is worth noting that the highest percentage of participants reported to choose to continue with online learning (Table 3). Online learning will surely continue to grow in the future. The findings are completely in line with a study [10] about future digital trends in ELT, reflecting that new development of technology will continue to affect English language teachers and learners.

Table 3. Future types of learning

\begin{tabular}{|c|c|c|}
\hline Continue with online learning & $\begin{array}{c}\text { Not continue with online } \\
\text { learning }\end{array}$ & Not certain \\
\hline $63.5 \%$ & $15.2 \%$ & $21.3 \%$ \\
\hline
\end{tabular}

\section{DISCUSSION AND CONCLUSION}

Retention of online learning is a concern of global education, and will continue to be a focus of many institutions. Retention is required for the long-term success of an institution. A high rate of learner dropouts is not only a fiscal problem, but a symbolic failure of an institution to achieve its purpose. The findings of this study indicate that online courses continue to grow in a rapid rate, and learner retention rates are relatively positive; however as online courses generally call for a greater amount of motivation and self-discipline than a classroom-based course, successful ways of measuring and improving student retention will continue to be sought.

The following recommendations may be offered based on the results: 
- Develop effective orientation programs to ensure that learners are well prepared both technically and practically to take online courses.

- Ensure that teachers are not only content experts but have a passion for teaching and are learner-centric.

- Provide at-all-times supports for learners in their programs and identify learners at risk of dropping out early so intervention efforts can be put into place.

- Build up online learning community for both academic and social interaction through chat groups such as Zalo to increase interaction between teachers and learners, and among learners.

- Develop programs or courses that allow for more flexible self-pacing. The flexibility of online education is often the most appealing factor, contributing to many learners choosing to opt for this mode of learning over a more conventional education.

Retention issue is quite complex, and it takes a collaboration to address it. The solution lies in increased efforts to meet the needs of online learners by implementing a cohesive plan in which program administrators, teachers and learner services should work together to ensure the success of this growing population of learners. An institution in which functional units combine efforts to support online learners will guarantee its success.

\section{REFERENCES}

[1] Carr, S. (2000). As distance education comes of age, the challenge is keeping the students. Chronicle of Higher Education, 46(23), 39-41. Retrieved from https://www.chronicle.com/article/as-distance-education-comes-of-agethe-challenge-is-keeping-the-students/

[2] Hagedorn, S. L. (2006). How to define retention: A new look at an old problem. Retrieved from https://eric.ed.gov/?id=ED493674

[3] Brown, M., Keppell, M., Hughes, H., Hard, N., \& Smith, L. (2013). Exploring the disconnections: Student interaction with support services upon commencement of distance education. The International Journal of the First Year in Higher Education, 4(2). 63-74. doi: 10.5204/intjfyhe.v4i2.171

[4] Online Statistics (2021). Online learning statistics in 2021. Retrieved from https://www.guru99.com/online-learningstatistics.html

[5] Lee, Y. \& Choi, J. (2011). A review of online course dropout research: Implications for practice and future research. Education Tech Research Dev, 59(1), 593-618.

[6] Boston, W. E., Ice, P. \& Gibson, A. M. (2011). Comprehensive assessment of student retention in online learning environments. Online Journal of Distance Learning Administration, 14(1). Retrieved from https://www.westga.edu/ distance/ojdla/spring141/boston ice_gibson141.html

[7] Varre, C., Irvin, M. J., Jordan, A. W., Hannum, W. H., \& Farmer, T. W. (2014). Reasons for student dropout in an online course in a rural K-12 setting. Distance Education, 35(3). 324-344. Retrieved from https://files.eric.ed.gov/fulltext/EJ1044355.pdf

[8] Yengin, I., Karahoca, D., Karahoca, A., \& Yucel, A. (2010). Roles of teachers in e-learning: How to engage students $\&$ how to get free-elearning and the future. Social and Behavioral Sciences, 2(2), 5775-5787. Retrieved from https://doi.org/10.1016/j.sbspro.2010.03.942

[9] Redmond, P., Hefferman, A., Abawi, L., Brown, A., \& Henderson, R. (2018). An online engagement framework for higher education. Online Learning, 22(1), 183-204. doi:10.24059/olj.v22i1.1175

[10] Hockly, N. \& Dudeney, G. (2018). Current and future digital trends in ELT. RELC Journal, 49(1), 164-178. doi: $\underline{10.1177 / 0033688218777318}$ 